\title{
LITERATURA, TEATRO E CINEMA: MEDIAÇÕES POSSÍVEIS PARA WILLIAM SHAKESPEARE NA SEGUNDA FASE DO ENSINO FUNDAMENTAL
}

\author{
Lemuel da Cruz Gandara ${ }^{1}$
}

\begin{abstract}
Resumo
Trazemos um panorama crítico-reflexivo sobre as aulas de literatura na segunda fase do ensino fundamental. Problematizamos a relação do professor junto às mídias contemporâneas para analisar questões relacionadas à leitura de fruição estética e às possibilidades de mediação entre os alunos e as obras literárias. Esses tópicos se convergem na prática docente realizada na turma do $8^{\circ}$ ano do Centro de Ensino e Pesquisa Aplicada à Educação (CEPAEUFG), na qual trabalhamos as peças teatrais Romeu e Julieta (1591/95) e Sonho de uma noite de verão (1595/96), ambas de William Shakespeare, e seus desdobramentos na arte e na cultura.
\end{abstract}

Palavras-chave: Ensino de Literatura; Segunda fase do ensino Fundamental; Arte; Mediação

\section{INTRODUÇÃO}

Ao observarmos a era da reprodutibilidade pensada por Walter Benjamin (2012), percebemos que a criança, em seus primeiros anos, entra em contato com inúmeros media, o que inclui o livro literário. Desse bojo, destacamos a televisão e os aparelhos que reproduzem filmes, na medida em que proporcionam uma forma mais imediata para os pais entreterem seus filhos. Essa reflexão serve para clarear que o "contar uma história" está em diversos meios para além da literatura.

\footnotetext{
${ }^{1}$ Licenciado em Letras Português e Bacharel em Estudos Literários pela Universidade Federal de Goiás (UFG). Mestre em Literatura pela Universidade de Brasília (UnB). Doutorando em Literatura pela mesma instituição. Professor tutor da Licenciatura em Letras da Universidade Aberta do Brasil (UAB/UnB). Endereço: QE 46 AE 03, Ed. Valentina 513-D, Guará II, CEP 71070-649, DF, Brasil. E-mail: gandara21@,hotmail.com
} 
Pré-adolescentes e adolescentes navegam em inúmeras redes sociais e criam avatares que os possibilitam "escreverem" suas próprias histórias. Assim, o tempo para a leitura de uma obra literária concorre com o tempo ágil e "moderno" de outros meios. Não queremos apontar que a literatura deve ser a prioridade absoluta para um aluno que tem, no mínimo, mais sete disciplinas para estudar; ao contrário, nossa reflexão parte do tempo reservado ao estudo literário, que, por si só, pode resultar em prazer e fruição estética dentro da sala de aula.

Será que a literatura está distante da realidade de nossas crianças, pré-adolescentes e adolescentes? Eles podem estar fadados à velocidade da sociedade de consumo e informação? Acreditamos que não. No entanto, cogitamos que algumas famílias não dão muita atenção à leitura de textos que permitam o desenvolvimento gradativo do gosto literário. Soma-se a isso a escola que, de acordo com sua ideologia, pode apresentar um cânone literário atrofiado ao aluno. Assim, a empreitada de ensinar literatura se mostra como uma dificuldade a mais ao professor, pois a responsabilidade de despertar o desejo pela leitura acaba se tornando árduo e até inconveniente para alguns. Mas prazeroso para outros.

No ambiente do ensino, percebemos o professor como um mediador entre a literatura e o aluno. A partir disso, nossa prática docente buscou estabelecer uma possível ponte entre o universo do alunado do $8^{\circ}$ ano do Centro de Ensino e Pesquisa Aplicada à Educação (CEPAE/UFG) e o monumento literário produzido pelo autor inglês da era elisabetana William Shakespeare (1564-1616). Nossas aulas foram elaboradas a partir das peças teatrais Romeu e Julieta (tragédia, 1591/95) e Sonho de uma noite de verão (comédia, 1595/96).

Buscamos conectar os temas das duas obras com a faixa-etária dos alunos (12 a 14 anos), os quais formavam um grupo de pré-adolescentes e adolescentes que se iniciavam no universo das relações afetivas e dos sentimentos amorosos. Após a leitura integral das obras, pontuamos as especificidades dos gêneros tragédia e comédia dentro da arte dramática e também procuramos utilizar os recursos midiáticos e artísticos da contemporaneidade, como o cinema e a internet. Feito isso, também exercitamos a escrita por meio de cartas escritas pelos discentes.

\section{O LUGAR DA LITERATURA NA ERA DA REPRODUTIBILIDADE}

No século XX, as artes assumiram um papel diferente de outros tempos. Segundo 
Benjamin "a forma mais primitiva de inserção da obra de arte no contexto da tradição se exprimia no culto" (2012, p.171). Compreende-se, assim, que durante séculos a arte acumulou um papel de cunho religioso. A partir da revolução industrial, passando pelo advento da fotografia e do cinema, "a obra de arte se emancipa, pela primeira vez, de sua existência parasitária, destacando-se do ritual [...] toda a função da arte se transforma" (BENJAMIN, 2012, p. 171). Com a transformação do homem, a sociedade mudou e a apreciação da arte acompanhou tal modificação.

\begin{abstract}
A natureza e a técnica, o primitivismo e o conforto se unificam completamente, e aos olhos das pessoas, fatigadas com as complicações infinitas da vida diária e que veem o objeto da vida apenas como o mais remoto ponto de fuga numa interminável perspectiva de meios, surge uma existência que se basta em si mesma, em cada episódio, do modo mais simples e mais cômodo, e na qual um automóvel não pesa mais que um chapéu de palha, e uma fruta na árvore se arredonda como a gôndola de um balão. (BENJAMIN, 2012, p. 119).
\end{abstract}

Se considerarmos a multiplicidade de compromissos que o indivíduo tem durante o dia, segundo Benjamin (2012), concluiremos que o homem tem pouco tempo para o descanso. Os instantes destinados ao entretenimento são mínimos e as diversões que exigem menos tempo, como o cinema e o teatro - para não citar o universo das redes virtuais -, ganham prioridade. Assim, a literatura vai ficando em segundo plano. Conforme Mario Vargas Llosa, não é a literatura de massa (que na sociedade de consumo é apenas mais um produto à venda) que consegue pouco espaço, mas a boa literatura, aquela que, além de proporcionar prazer, possibilita ao homem uma reflexão sobre seu comportamento diante do mundo, além de contribuir com a fortuna literária de um povo (2009). Apesar de considerarmos essa posição do autor de Pantaleão e as visitadoras (1973) um tanto problemática devido ao julgamento do que é bom ou ruim na arte literária, concordamos que obras basilares do ocidente perdem lugar nas estantes das lojas e nos currículos das escolas.

Llosa, no texto Em defesa do romance (2009), escrito para a revista Piauí, aponta o seguinte:

A literatura acabou por se tornar, cada vez mais, uma atividade feminina: nas livrarias, nas conferências ou nas readings dos escritores e, naturalmente, nos departamentos e nas faculdades em que se estuda literatura, as saias ganham de goleada das calças. A explicação é que, na classe média, as mulheres leem mais porque trabalham menos horas que os homens, e que muitas delas tendem a se considerar mais justificadas do que os homens no tempo que dedicam à fantasia e à ilusão. [...] Há cada vez menos leitores de literatura - há muitos leitores, mas de lixo 
impresso - e, entre eles, as mulheres prevalecem. (2009, p. 1).

Percebemos, assim, onde a literatura está inserida na era da reprodutibilidade. A visão de Llosa se mostra possível ao retratar algo que deveria nos causar incômodo. As ávidas leitoras da classe média que consomem o livro do momento são índices para uma discussão profunda sobre a situação em que se encontra a literatura. O que anda sendo escrito de consistente e como esses escritos dialogam com o que já foi construído por outros autores. A constatação pessimista do peruano vai ao encontro do crítico europeu George Steiner quando este último afirma: "Temos que admitir a possibilidade de que o estudo e a transmissão da literatura sejam apenas de significado marginal, um luxo sentimental, como a preservação de antiguidades" (1988, p. 24). Essas duas reflexões podem se mostrar catastróficas, mas são importantes para compreendermos, enquanto professores, como não proceder no ensino de literatura e na formação do senso crítico estético dos alunos.

Mesmo com um horizonte nada otimista, uma saída é transmitir para os alunos o mesmo sentimento que nos provoca e nos torna um desses protetores de tal relíquia cultural: “A arte da leitura, do verdadeiro alfabetismo, deve ser reconstituída" (STEINER, 1988, p. 29). Podemos delinear um projeto com vistas à base do ensino, já que temos o privilégio de ensinar literatura às crianças e adolescentes, de trabalhá-la segundo leituras, teorias e críticas distintas (o que inclui também o alunado). Para isso, se torna necessário compreender nosso tempo e diminuir os conflitos geracionais para assim criar uma ponte sólida entre a literatura e os nossos alunos. Talvez assim podemos atualizar o hábito de ler "boa literatura". Nesse horizonte, um dos momentos fulcrais para a educação literária é o ensino fundamental.

\section{A LITERATURA NO ENSINO FUNDAMENTAL}

A Lei de Diretrizes e Bases da Educação (Lei 9.394, de 20 de dezembro de 1996) resguarda ao cidadão o direito de desenvolver "a capacidade de aprender, tendo como meios básicos o pleno domínio da leitura, da escrita e do cálculo" (LDB, p.42). Com a organização das áreas do conhecimento no currículo nacional para este nível de ensino, a premissa dela se alargou. Assim, foram elaborados os Parâmetros Curriculares Nacionais (PCN) para direcionar o ensino no país, porém pouco favoreceram a arte literária.

Os PCN foram forjados para preencher a lacuna entre a lei e a efetivação da prática docente no ensino fundamental (primeira e segunda fase) e no ensino médio. No nosso caso, a 
atenção recai sobre o PCN para a área de Língua portuguesa, com foco no tratamento dado à literatura na segunda fase do ensino fundamental. Ao pensar o lugar reservado à literatura nessa fase do ensino, chega-se a duas conclusões. A primeira tem a ver com o distanciamento das reflexões sobre o assunto, o que é percebido principalmente nos PCN. A segunda é justamente as possibilidades que essa distância potencializa. Ou seja, como os PCN para a segunda fase do ensino fundamental $\left(6^{\circ}\right.$ ao $9^{\circ}$ ano) consideram todo texto exclusivamente como gênero textual, sem particularizar o literário, temos uma oportunidade de trabalhar em sala de aula várias reflexões sobre a literatura partindo de sua perspectiva enquanto gênero textual narrativo ou poético.

$\mathrm{Na}$ primeira fase do fundamental, o texto literário tem sua especificidade na educação:

É importante que o trabalho com o texto literário esteja incorporado às práticas cotidianas na sala de aula, visto tratar-se de uma forma específica de conhecimento. Essa variável de constituição da experiência humana possui propriedades compositivas que devem ser mostradas, discutidas e consideradas quando se trata de ler as diferentes manifestações colocadas sob a rubrica geral de texto literário. (PCN, p. 29).

No recorte, percebemos que o lugar destinado à obra literária gera uma tensão. $\mathrm{O}$ fato é relevante se pensarmos que tais $\mathrm{PCN}$ abrangem do $1^{\circ}$ ao $5^{\circ}$ ano da primeira fase do nível fundamental (momento em que os alunos estão iniciando no letramento) e que muitas vezes o professor recorre ao texto literário somente para o ensino da leitura. Se nessa fase o problema incorre na abordagem estanque do texto literário, na segunda fase o problema é a falta de espaço à literatura, que é retomada somente quatro anos depois no ensino médio.

Os PCN destinados à segunda fase do ensino fundamental refletem sobre o texto como um todo de sentido. Porém, o texto literário pode se perder no horizonte dos gêneros textuais. Logo, pode-se definir que o ensino de literatura nessa fase representa um problema, pois os professores que não consideram as sutilezas do texto literário diante dos outros gêneros podem contribuir para o desinteresse do aluno pela literatura. A falta de alusão à literatura na segunda fase do ensino fundamental não pode ser vista apenas como impasse, pois o professor, em sala de aula, pode preencher o vazio deixado pelos PCN.

O papel do professor, conforme os PCN, é de "facilitador no processo de busca de conhecimento que deve partir do aluno. Cabe ao professor organizar e coordenar as situações de aprendizagem, adaptando suas ações às características individuais dos alunos, para desenvolver suas capacidades e habilidades intelectuais" (p. 31). Se ao professor é reservada 
tal função, será de grande valor trabalhar o texto literário, pois o aluno pode apreender capacidades intelectuais da língua enquanto representação do homem e do seu lugar no mundo, além de entrar em contato com inúmeras representações da vida na arte. Conforme Bakhtin (2003, p. XXXIV), "arte e vida não são a mesma coisa, mas devem tornar-se algo singular em mim, na unidade da minha respondibilidade”. Essa respondibilidade tem a ver com a resposta que o leitor dá a obra literária, ou seja, como ele a atualiza conforme seu contexto. Dessa maneira, o professor (que também é um leitor), ao trabalhar literatura em sala de aula, responde pedagógica e esteticamente ao texto.

Um dos parâmetros principais dos PCN é que o "aluno possa ser sujeito de sua própria formação, em um complexo processo interativo em que também o professor se veja como sujeito de conhecimento" (p. 32). Se o docente é o sujeito que detém o conhecimento a ser transmitido em uma mediação que visa o enriquecimento humano e intelectivo do discente, logo ele não pode perder de vista a literatura já que ela é um dos meios seculares de se chegar a tais objetivos. Estes são possíveis pela fruição estética, que, em um viés bakhtiniano, são alcançados com a vivência da experiência do personagem e de seu mundo através da contemplação, "é a vida do outro vivenciada essencialmente de fora" (2003). Logo, a fruição estética em sala de aula não se dá apenas com a leitura e o reconhecimento do código linguístico, mas também com a vida e as experiências do leitor (professor e aluno) diante do acabamento estético literário, isto é, sua interpretação e atualização no intelecto e seu ativismo, que, no nosso entendimento, pode estar na prática docente do professor e nas atividades realizadas pelos alunos.

No cenário obscuro em que a literatura está inserida, concluímos que, no ensino fundamental, alguns professores estão negando o direito à arte literária aos alunos. Isso, talvez, em razão de ela também ter sido negada a eles. Antonio Candido, em seu texto "O direito à literatura" (1995), defende que ela é um objeto de valor necessário ao homem, assim como os bens básicos para sua sobrevivência. Candido ainda considera que "uma sociedade justa pressupõe o respeito dos direitos humanos, e a fruição da arte e da literatura em todas as modalidades e em todos os níveis é um direito inalienável” (1995, p. 263). Sendo assim, o professor, ao "esquecer" a literatura, acaba por tirar o direito que o aluno tem de conhecê-la.

\section{O PROFESSOR COMO MEDIADOR}


Com os questionamentos acerca do pequeno espaço reservado à literatura no ensino fundamental, chega-se à reflexão sobre o lugar do professor nesse âmbito. Na atual conjuntura pedagógica, a mediação é a palavra-chave, pois reporta ao docente como um sujeito hábil para conectar o aluno à obra literária.

Ao levar o texto literário para a sala de aula, o profissional da educação deve estar ciente de que ele é plural de significados e cheio de singularidades. Por isso, de acordo com Braga, "nossas responsabilidades enquanto mediadores da leitura é desenvolver a noção de que a literatura dialoga e poetiza a história social, mas nunca a reproduz fielmente e, devemos, por isso, promover o ensino da arte literária enquanto objeto estético" (2006, p. 04).

Os media, na contemporaneidade, não são empecilhos para a leitura de um texto. Sempre existiram agentes extrínsecos que direcionavam o leitor para outros lados. Segundo Daniel Pennac, se o século XXI é tido como o das imagens, o XIX foi o da discrição, o XVIII da racionalidade, por sua vez o XVII clássico demais, o XVI renascença demais (2008, p. 38). A arte literária sempre encontrou obstáculos, no entanto acabou por fazer parte de todo o processo cultural do homem, em qualquer tempo e espaço. Portanto, o professor, como mediador diante da obra literária, pode e deve levar em consideração o contexto dos alunos.

Pennac ainda assevera que a antiga relação professor-literatura-aluno, em que o professor "espera que os alunos apresentem boas fichas de leitura sobre romances que ele lhes impõe, que 'interpretem' corretamente os poemas que escolhe, que no dia do exame analisem finamente os textos de sua lista" $(2008,45)$, não se adapta no atual contexto e muito menos beneficia na formação de leitores. O texto não está dentro do livro à espera que o interpretem segundo uma cartilha. O raciocínio é bem diferente. O texto está à espera de um leitor, e este, por sua vez, está inserido em um contexto. Ainda segundo Daniel Pennac, quando, enfim, um aluno se torna, de fato, um bom leitor, o professor sabe que o mérito não é seu, na verdade o desejo pela leitura já estava no aluno, o professor apenas o estimulou.

Ao propor a leitura de uma obra literária para os alunos, o professor tem que se atentar à importância da leitura integral do texto, seja ele um romance, um conto ou um poema. Alves (2006) afirma que o texto literário deve ser o principal foco no ensino de literatura. Essa posição se mostra como ponto elementar para observarmos a postura tomada pelo professor e pela escola, tendo-se em vista que ambos podem se transformar o livro didático em bengala e, por isso, desprezar o texto de partida, que é exclusivo da literatura.

Ao ler a obra literária e apreender os sentidos dela através da mediação, o indivíduo 
começa a ler o mundo com olhos críticos. Segundo Freire, "a libertação autêntica, que é a humanização em processo, não é uma coisa que se deposita nos homens, não é uma palavra a mais, oca, mitificante. É práxis, que implica a ação e a reflexão dos homens sobre o mundo para transformá-lo" (1987, p. 77). A citação é pertinente para uma observação sobre o papel humanizador da literatura, fato que Mário Varga Llosa (2009), Antonio Candido (1995; 2002) e George Steiner (1988) já chamaram a atenção e que Bakhtin e Paulo Freire reafirmam. O homem se humaniza com o saber, e a literatura tem grande função no processo de desvendar o outro e de olhar para o mundo com menos ingenuidade.

No que se refere ao processo de mediação nos vieses pedagógicos, para Freire, "o educador já não é o que apenas educa, mas o que, enquanto educa, é educado, em diálogo com o educando que, ao ser educado, também educa. Ambos, assim, se tornam sujeitos do processo em que crescem juntos e em que os 'argumentos de autoridade' já não valem” (1987, p. 79). A consideração aponta para um horizonte em que o professor-mediador, ao ler a obra com os alunos, constrói uma interpretação conjunta. A interpretação dos alunos acrescentará outras perspectivas à leitura do professor, ampliando a pluralidade de significados da obra.

O professor, assim, é um mediador que se encontra em um entrelugar, sendo responsável por conectar os alunos com o cânone escolar e também com a própria arte literária que está distante da canonização, mas que possibilita horizontes nos quais o prazer é possível de ser alcançado. O professor-mediador é como um filtro das obras literárias. Ele apresenta as especificidades de uma obra, acompanha de perto a recepção dela pelos alunos, e chama a atenção para as possíveis interpretações. Por essa razão, professores e alunos desempenham juntos a função de crítico, pois acrescentam outras perspectivas à fortuna de leituras de determinada obra ou escritor.

Pelo que foi exposto, a segunda fase do ensino fundamental não deve ser considerada somente um tempo escolar em que a objetividade da língua é o único foco. O espaço da sala de aula tem por responsabilidade a educação literária do aluno, à medida em que os próprios PCN, com sua "exclusão da literatura", viabiliza uma abordagem por vezes até mais ampla que a do ensino médio, pois ela não se limita às obras canônicas brasileiras e muito menos tem compromisso com os livros dos exames vestibulares.

Logo, nesse campo incerto, surge uma oportunidade única para o professor mediar o acesso dos alunos à literatura. Não somente isso, com as leituras o aluno terá seu direito à obra literária respeitado. Dessa forma, o ainda alunado pode não perceber, mas estará 
entrando em contato com uma visão mais vasta do mundo, o que pode render bons frutos para ele e para a sociedade, afinal, nas palavras de Antonio Candido, a literatura "não corrompe nem edifica, portanto; mas, trazendo livremente em si o que chamamos o mal, humaniza em sentido profundo, porque faz viver" (2002, p. 85).

\section{WILLIAM SHAKESPEARE NA SALA DE AULA}

Com o desígnio de ensinar literatura, provocar reflexão sobre a língua e a arte e educar para a vida, o professor-mediador tem que procurar obras literárias que dinamizem e sintetizam tais abordagens. Por essa razão, o momento de escolha dos textos se mostra delicado no processo de elaboração da ementa. No que diz respeito as escolhas, os considerados textos clássicos nacionais terminam por ser uma obviedade, mas nada exclui o acréscimo de obras da literatura estrangeira. Assim, o aluno, desde cedo, já estaria convidado a conhecer autores como William Shakespeare.

A recepção do texto pelos alunos é um dos grandes temores de qualquer professor, porém a mediação faz toda diferença nessa etapa. Nesse âmbito, conforme assevera Bárbara Heliodora ao ser questionada sobre ensinar Shakespeare, "depende muito da capacidade do professor de criar interesse" (2001, p. 392). O fator primário para se ter em vista é o proposital distanciamento do livro didático. No texto literário está tudo o que o mediador precisa para o sucesso da recepção, pois os alunos, enquanto leitores, são parte fundamental na fenomenologia da arte. Por meio dessa visão sobre o aluno-leitor e o professor-mediador, a obra literária se mostra como solução e como algo a ser desvendado aos poucos durante a leitura íntima e nas aulas.

Assim, a leitura dos clássicos é um bom norte para o professor. Ela, além de mediar o contato com o cânone, o atualiza. Nesse cenário, a leitura das peças Romeu e Julieta e Sonho de uma noite de verão, ambas de Shakespeare, não somente contribui para a compreensão das especificidades do gênero dramático, como também possibilita uma discussão sobre o amor e as dificuldades relacionadas a esse sentimento, principalmente quando lidas na segunda fase do ensino fundamental, momento em que, geralmente, os alunos estão iniciando as relações amorosas.

Para Italo Calvino, a leitura na juventude marca o primeiro encontro do leitor com os clássicos, segundo o autor, 
de fato, as leituras da juventude podem ser pouco profícuas pela impaciência, distração, inexperiência das instruções para o uso, inexperiência da vida. Podem ser (talvez ao mesmo tempo) formativas no sentido de que dão uma forma as experiências futuras, fornecendo modelos, recipientes, termos de comparação, esquemas de classificação, escalas de valores, paradigmas de beleza: todas, coisas que continuam a valer mesmo que nos recordemos pouco ou nada do livro lido na juventude. (1993, p. 10).

Nesse sentido, o professor precisa ter uma cruel certeza de que a aula, a obra clássica ou as discussões podem não seguir com o aluno durante o percussor de sua vida, entretanto não lhe foi negado esse "antigo talismã".

A necessidade da leitura de clássicos shakespearianos na era da reprodutibilidade se mostra importante, ainda que a nossa sociedade, marcada pelo consumo e o imediatismo, procure minimizar tudo e tornar efêmera e fugaz qualquer relação. A obra de arte deve persistir "como rumor mesmo onde predomina a atualidade mais incompatível" (CALVINO, 1993, p. 25). De acordo com esse raciocínio, os textos do autor inglês do período elisabetano (1558-1603) têm sempre o que dizer não importa o tempo e nem a sociedade, elas devem ser lidas para uma melhor compreensão das coisas mundanas e do comportamento humano.

O professor-mediador não deve perder de vista os clássicos. Será que um aluno da segunda fase do ensino fundamental não consegue as obras de Shakespeare? Acredita-se que, por mais que o leitor nessa fase possa se envolver somente com a narrativa, ele, mesmo assim, consegue obter alguma fruição estética. O que não pode ser feito é “esquecer" de apresentá-la aos alunos. Não se deve esperar a leitura idealizada, já que cabe aos estudantes acadêmicos de Literatura e ao professor de língua portuguesa saber mais profundamente as questões literárias. O aluno está mais "livre" nesse processo, afinal a literatura deve lhe trazer um gozo ou uma inquietação e não obrigações relativas ao aprendizado. $\mathrm{O}$ professor, assim, tem a oportunidade de iluminar a obra de Shakespeare, fazê-la se atualizar na contemporaneidade.

\section{OS MEDIA E O ENSINO DE LITERATURA}

Tendo salientado a função do professor-mediador e feito uma reflexão sobre Shakespeare, deve-se levar em consideração o ensino de literatura e os media reprodutíveis. Com as rápidas mudanças tecnológicas, a relação do homem com o mundo mudou, porém as reverberações na educação são mais lentas. Não se pode perder de vista que as novas 
tecnologias fazem parte do cotidiano dos alunos. Mesmo assim, boa parte dos professores, principalmente do ensino público, ainda não se relacionam com os novos meios de ensino.

\begin{abstract}
É verdade que nas últimas duas décadas tem-se questionado intensamente seja a figura do professor que dita unidirecionalmente a aula seja o alheamento às novas linguagens. A difusão dos pressupostos dialógicos, interacionistas e construtivistas promoveu a revisão de práticas que viam nos alunos receptores passivos do discurso pedagógico legitimado e nos códigos verbais a única possibilidade de constituir a experiência educativa formal. (CITELLI, 2000, p. 33).
\end{abstract}

Tal consideração contribui para a ilustração dos novos paradigmas que envolvem o relacionamento entre o professor-aluno/aluno-mundo. Não se pode negar que os media, como "comunicação feita recorrendo a dispositivos técnicos de comunicação" (SOUSA, 2006, p.35), promoveram a dinamização do conhecimento. Os alunos podem pesquisar em sites sobre os temas discutidos em aula e comunicam entre si com mais agilidade através de $e$ mails, redes sociais e celulares. Por isso, é necessária uma postura mais "atualizada" do professor na elaboração das aulas. Por mais que o espaço virtual ofereça um bom cenário para trocar conhecimentos, ele está “desorganizado", e é preciso o professor ajudar a "organizá-lo" junto aos alunos no exercício da aula.

\footnotetext{
Nos media, apresentam-se decisões que nos afectam, personalidades que nos lideram ou servem de modelo, ideias e ideologias. Nos media, fala-se de política, economia, ciências, educação, trabalho, leis, arte, sociedade, culturas, pessoas, lugares, ideias... A riqueza de informação permite a construção de conhecimentos sólidos sobre a realidade por aqueles que a souberem aproveitar. (SOUSA, 2006, p. 491).
}

Assim, em uma interpretação do fragmento, não se pode ir contra a tecnologia, nem se deve ignorar a questão de que vivemos em uma época de mais informações e meios de propagação destas. O importante é saber aproveitar esse momento. Nesse sentido, uma visão distorcida é a de que os alunos leem com menos frequência que em tempos passados em razão de as páginas dos livros serem numerosas ou por preferem ver um filme ou jogar videogame. Compreendemos que são afirmações coerentes; no entanto, será que foi observado que as sagas famosas como Harry Potter ou os romances de Nicholas Sparks exigem tempo de leitura dos alunos? O problema não é a pouca atenção dada à literatura, mas a mínima atenção dispensada às literaturas desafiadoras e esteticamente estimulantes. Diante dessa perspectiva, o professor interessado em promover a educação estética no ensino fundamental acaba por ter nas mãos uma oportunidade única de mudar o processo e formar leitores mais conscientes do 
que estão lendo.

Um dos maiores problemas da "preguiça intelectual" do alunado (ou mesmo do professorado) é o uso inadequado do audiovisual enquanto recurso pedagógico. Alguns professores ignoram a leitura da obra literária e vão direto à tradução fílmica, ou acabam por desprezar o filme como representante de uma leitura da obra. O impasse, nesse caso, é a relação com o media, seja o livro, o filme ou a internet. A respeito disso, já na década de 80 , Giacomantonio afirma que:

\footnotetext{
Sendo empregada a didática da imagem na escola, na própria classe, para desenvolver as atitudes de pesquisa, conhecimento e comunicação dos jovens, pouco importará se os primeiros experimentos serão 'maus' 'enfadonhos' ou tecnicamente decadentes; serão de todo modo muito bonitos, pois representarão os resultados de um trabalho desenvolvido em comum no processo de aprendizagem. (1981, p. 20).
}

Mais de trinta anos depois, e em contexto similar, o projeto de extensão "Mídia e educação: o audiovisual na sala de aula", do Laboratório de Investigação do Audiovisual (LIA) da Universidade Federal Fluminense (UFF) chamou atenção para o mesmo tema. Segundo Siqueira e Ribeiro, "hoje não é mais possível deixar as experiências dos indivíduos com a mídia para fora das instâncias de educação formal” (2007). As duas posições críticas corroboram que não se pode olvidar o fato de a apreciação do audiovisual ou das imagens, em sua maioria, ser coletiva. Além disso, ela tem perspectivas diferentes de leitura que, se bem analisadas e discutidas, podem enriquecer a aula e os argumentos tanto dos alunos quanto dos professores. Ademais, os media, com atenção aos audiovisuais, não são concorrentes da literatura e, por contemplarem noções distintas de representação do indivíduo, propiciam outra relação entre o sujeito e o objeto artístico.

Então, para uma aula mais coerente com a era da reprodutibilidade, o professor deve ter em mira as várias possibilidades que surgiram com a cultura das mídias, conforme Santaella (2008), e as ciências tecnológicas, por exemplo, o cinema, os aparelhos de reprodução digital de imagens, a internet e a própria literatura. Entretanto, o foco principal deve ser dado à obra e arte literária, sendo os "acessórios" contemporâneos um complemento no processo de mediação.

\section{PERSPECTIVAS DE MEDIAÇÃO NA SALA DE AULA}


A prática docente aqui relatada tem por objetivo apresentar possibilidades concretas de mediação para a educação literária na segunda fase do ensino fundamental. Ela partiu dos pressupostos apresentados, como a fragilidade dos PCN no que se refere ao ensino de literatura e o advento dos medias, fatos que, aliados ao desejo de mediar o acesso à arte literária, nos motivou a elaborar aulas dinâmicas que se adequassem à faixa etária do alunado e à agilidade do nosso tempo, sem perder de vista a leitura integral das obras clássicas selecionadas.

No Centro de Ensino e pesquisa Aplicada à Educação (CEPAE-UFG), a prática foi desenvolvida na turma do $8^{\circ}$ ano da segunda fase do ensino fundamental durante o ano letivo de 2012. Notamos que, entre os livros da ementa, havia a peça Romeu e Julieta, de William Shakespeare, e a adaptação para o público infanto-juvenil de Sonho de uma noite de verão, recontada por Charles e Mary Lamb, que integra a seleção de contos Histórias de amor, da coleção Para gostar de ler. Procuramos dividir o estudo das obras em dois momentos. No primeiro semestre do ano, trabalhamos seis aulas com Romeu e Julieta. No segundo semestre, a mesma quantidade de aulas com Sonho de uma noite de verão. Elaboramos duas sequências didáticas divididas em tragédia e comédia.

\subsection{Tragédia: Romeu e Julieta}

Estabelecer as diferenças entre o gênero literário e o cinematográfico era um dos objetivos em relação à linguagem era um dos objetivos do curso. Para tanto, a análise da peça Romeu e Julieta partiu de uma reflexão sobre a literatura comparada, levando em consideração o audiovisual. Os alunos tiveram dois meses para ler a peça. Após boa parte dos alunos terem feito a leitura integral do texto, resolvemos reservar o Cine UFG (cinema localizado no prédio da Faculdade de Letras da Universidade de Goiás - FL/UFG) para a Mostra Shakespeare, que exibiria o filme de longa-metragem Romeu+Julieta (Romeo+Juliet, EUA, 1996) dirigido por Baz Lhurmann e roteirizado por ele e Craig Pearce; e o documentário $O$ essencial de Shakespeare, que se trata de uma seleção de vários documentários em curta-metragem que exploram o universo ficcional do dramaturgo.

Apesar de o CEPAE-UFG fornecer artefatos tecnológicos para a exibição do filme, como Datashow, preferimos exibir a obra em sua mídia original para observar o processo de recepção dos alunos, e também para discutirmos em sala de aula as diferenças de linguagem 
entre literária e cinematográfica e os media livro e cinema. O intuito principal foi levar os alunos a pensarem sobre a independência do cinema, e não enxergá-lo como um "parasita" da literatura no processo de tradução coletiva do texto literário. Ou seja, queríamos levar a cabo a emancipação das artes ditada por Walter Benjamin no cenário do mass media, o qual potenciou a indústria cultural preconizada pela escola de Frankfurt.

A aula seguinte foi elaborada com vistas a direcionar os alunos a notarem, no cotidiano, a presença constante de fatos relacionados a Romeu e Julieta. Também salientamos o estudo sobre o gênero tragédia e suas especificidades a partir dos estudos sobre os gêneros textuais dispostos nos PCN. Iniciamos a aula com uma discussão a respeito da peça. Os alunos focaram suas atenções na relação de amor que parece ser ultrapassada para nossa realidade. Para desmitificarmos isso, procuramos situar a narrativa, levando em consideração o gênero trágico e a mensagem principal. Nesse momento, fizemos uma mediação para que os alunos entendessem o "porquê" da importância de tal história até hoje. Ressaltamos a mensagem universal do amor proibido, tema que influenciou várias histórias da literatura ocidental e que tem na referida obra uma de suas mais famosas representações.

Buscamos, na contemporaneidade, traços que ajudaram o casal de Verona ser lembrado durante o passar dos séculos. Mostramos as adaptações para outras manifestações artísticas, por exemplo, a dança e a ópera; além de outras versões, como a da escritora Ruth Rocha e a do gibi Turma da Mônica, de Mauricio de Souza. Podemos considerar que a parte mais relevante foi a reflexão sobre as referências a Romeu e Julieta na gastronomia. Pedimos aos alunos que analisassem as motivações que levavam a maioria dos pratos culinários inspirados na obra a ter como base alimentos nas cores branco e vermelho. Chegou-se à conclusão de que o branco representava a paz entre as famílias, e se considerarmos nossos dias, a paz entre as nações. A cor vermelha, por sua vez, representava o amor, e também simbolizava o sangue derramado na guerra entre os Montecchio e os Capuleto.

Tais discussões nos fizeram lembrar o que já discutimos sobre a ideia de Paulo freire (1987) na relação de mediação. Por mais que tivéssemos uma ideia prévia para a análise, foi na sala de aula que ela se apresentou de fato. Ou seja, não levamos o conhecimento pronto, com uma leitura única acerca da obra, mas procuramos mediar uma boa compreensão da obra lida, usando as referências a ela no cotidiano para, assim, os alunos entenderem as razões que tornaram Romeu e Julieta um mito literário que, como afirma Italo Calvino (1993), tem sempre o que falar, em qualquer tempo e espaço. 
Depois de uma análise mais detida na história e no mito do amor, procuramos realizar uma aula sobre a comparação entre o texto fílmico e o texto da tragédia. Para isso, levamos um handout que apresentava o recorte de uma cena. A atividade trazia o trecho da peça em que Romeu e Julieta, após a primeira e única noite de amor, se despedem:

\footnotetext{
Peça teatral Ato III, cena V

O mesmo. Quarto de Julieta. Entram Romeu e Julieta.

JULIETA - Já vais partir? O dia ainda está longe. Não foi a cotovia, mas apenas o rouxinol que o fundo amedrontado do ouvido te feriu. Todas as noites ele canta nos galhos da romeira. É o rouxinol, amor; crê no que eu digo.

ROMEU - É a cotovia, o arauto da manhã; não foi o rouxinol. Olha, querida, para aquelas estrias invejosas que cortam pelas nuvens do nascente. As candeias da noite se apagaram; sobre a ponta dos pés o alegre dia se põe, no pico das montanhas úmidas. Ou parto, e vivo, ou morrerei, ficando.

JULIETA - Não é do dia aquela claridade, podes acreditar-me. É algum meteoro que o sol exala, para que te sirva de tocheiro esta noite e te ilumine no caminho de Mântua. Assim, espera. Não precisas partir assim tão cedo. (SHAKESPEARE, 2004, p. 147)
}

\section{Cena do filme Romeu + Julieta}

JULIETA - Quereis ir? Não amanhece ainda.

ROMEU - Terei que ir e viver, ou ficar e morres.

JULIETA - A luz além não é a luz do dia, conheço - a, eu. É como que um meteoro que o sol exala para vos alumiar no vosso caminho para Mântua. Aguardai, pois, é cedo ainda. (01:19:00)

Procuramos levar tal momento para a análise pois há uma importante modificação para ele funcionar no cinema. No texto cinematográfico, as aves rouxinol (nightingale) e cotovia (lark) foram elididas. Discutimos, então, os possíveis motivos, para isso. Junto com os alunos entendemos de o filme fora realizado com vistas ao grande público (mass) e culturas diferentes, como os pássaros citados são mais específicos da Inglaterra, país do autor, optouse por tirá-los do texto. Outra percepção foi a do tempo, enquanto o texto, na sequência teatral, é mais longo, respeitando o desenvolvimento do trágico, no cinema ele é menor, uma vez que os recursos audiovisuais complementam os linguísticos.

Como atividade, produzimos cartas endereçadas a Julieta. Essa prática secular é o plot do livro best-seller Cartas para Julieta, de Lise e Ceil Friedman, adaptado para o cinema sob a direção de Gary Winick. O filme já havia chegado às locadoras e boa parte dos alunos já havia o assistido por influência das aulas anteriores sobre Romeu e Julieta. A carta, assim, consistia em relatar para a interlocutora Julieta problemas amorosos. O envolvimento da turma redeu bons textos e neles constatamos que os alunos tinham apreendido a peça dentro dos limites que pretendíamos. 
As aulas para a análise de Romeu e Julieta se mostraram satisfatórias. Os alunos entenderam as motivações para a permanência do texto e não o encararam como uma obra "ultrapassada". Os recursos contemporâneos foram acessados com harmonia, pois usamos o cinema e outros meios como a internet, na confecção dos handouts. Além disso, encontramos o texto integral no site domíniopúblico.gov.br, o que ajudou na elaboração e na recepção das discussões. Assim como refletiram Giacomatonio (1981) e Siqueira e Ribeiro (2007), procuramos promover um encontro prazeroso e consistente entre as duas linguagens, o audiovisual e a literatura.

\subsection{Comédia: Sonho de uma noite de verão}

A leitura da peça Sonho de uma noite de verão foi realizada no segundo semestre de 2012. Como já tínhamos apresentado Shakespeare para os alunos na sequência didática anterior, partimos direto para o texto. Os alunos tiveram dois meses para a leitura da obra. $\mathrm{O}$ texto não constava na ementa, pois era para ser lida a adaptação para o público infantojuvenil. A opção que encontramos foi usar a versão disponível em domínio público. Como a maioria dos alunos tinha acesso à internet, disponibilizamos o site onde estava o texto integral. Alguns alunos o imprimiram e o levavam para as aulas antes mesmo de começarmos os estudos, ou seja, a mediação para encontrar o livro no desorganizado espaço virtual acabou por guiá-los na procura, no encontro e na formatação do texto para a leitura.

Como mediadores, resolvemos distribuir cópias do texto integral para alguns alunos e realizamos a leitura dramática em sala de aula. Foi muito gratificante observar a recepção dos alunos, as risadas ecoavam nos momentos mais engraçados e a atenção se mantinha inalterada no decorrer da leitura. Foi uma prática de risco, pois durante as duas aulas, ao invés de ler o texto integral poderíamos ter realizado atividades mais "práticas", como as de cunho gramatical.

Os resultados foram satisfatórios, mas a compreensão do texto poderia ter sido melhor. Os vários personagens da peça e a trama entrelaçada entre os casais principais deixaram alguns alunos confusos. Para que isso fosse resolvido, na aula seguinte, buscamos usar o datashow na projeção de textos e imagens sobre a obra. Partimos do poema Quadrilha, de Carlos Drummond de Andrade: 


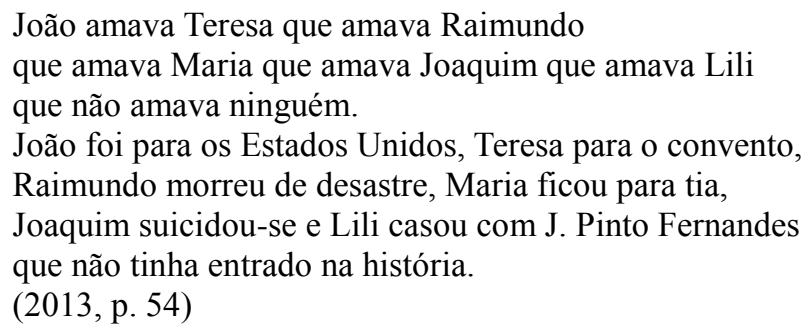

No texto poético, o sujeito lírico relata histórias de amor que se aninham, porém chegam a um desfecho mais próximo do trágico. A partir do entrelaçamento dos casais na trama procuramos recriar o mesmo clima da poesia com o enredo da peça, tal abordagem deixou a história mais clara para os alunos.

Partindo da leitura da comédia e da discussão sobre o amor, organizamos a Serenata literária. A atividade consistia na apresentação, pelos alunos, de casais famosos da literatura ocidental. Organizamos cinco grupos de alunos que pesquisariam sobre cinco casais famosos do universo da ficção literária: Ulisses e Penélope (Odisseia, de Homero), Dante e Beatriz (A divina comédia, de Dante Alighieri), Ceci e Peri ( $O$ guarani, de José de Alencar), Capitu e Bentinho (Dom Casmurro, de Machado de Assis), Riobaldo e Diadorim (Grande sertão: veredas, de João Guimarães Rosa). O objetivo era que as apresentações despertassem o interesse dos alunos pela leitura dos livros discutidos.

A pesquisa que eles realizariam era simples, consistia em ler e explicar o resumo da obra, apontar algumas características que tornaram a obra e o casal famosos, além de refletir como a história dialoga com o nosso tempo. Era de nossa consciência que a apresentação seria difícil para os alunos; ademais, tal atividade tinha quase uma função de "propaganda" para a leitura das obras mediada pelos próprios alunos. Tivemos uma grata surpresa. Alguns grupos pesquisaram com seriedade sobre os casais, ainda que a principal fonte tenha sido a internet. Como professores, complementávamos algumas discussões e iniciávamos outras, sem perder de vista o sucesso da mediação para a leitura dos textos no futuro. Procuramos não negar o direito que os alunos têm de conhecer a obra literária, como defendido por Antonio Candido (1995).

$\mathrm{Na}$ aula seguinte, fizemos uma reflexão sobre o conto adaptado da peça, o qual os alunos haviam lido individualmente. Levamos em consideração o gênero comédia e a diferença em relação ao trágico estudado no semestre anterior, além dos pontos convergentes e divergentes entre a peça teatral e o conto adaptado para o público infanto-juvenil. Chegamos à conclusão de que a construção estética da linguagem era a maior diferença entre os dois 
gêneros textuais, no conto alguns personagens foram substituídos e outros não aparecem.

Para a atividade final, realizamos um exercício que consistia na reflexão sobre as diferenças entre a linguagem do poema e da peça de teatro, os alunos também deveriam passar um recorte da peça para o discurso indireto, o que se assemelha ao processo de adaptação da peça para o conto. Os resultados das atividades foram surpreendentes, dentre eles o que mais nos chamou a atenção foi que, no final da prática docente, alguns alunos nos procuraram para mostrar que haviam retirado algumas das obras discutidas em sala na biblioteca da escola, o romance que despertou mais interesse foi Dom Casmurro, de Machado de Assis. Com isso, chegamos ao nosso objetivo principal, mediar o acesso do aluno à literatura.

\section{CONSIDERAÇÕES FINAIS}

Após todo o processo de reflexão sobre os PCN, as discussões críticas-reflexivas sobre o ensino de literatura, a problematização dos recursos contemporâneos e a experiência da prática docente no CEPAE-UFG, chega-se às considerações finais com uma certeza incontestável: a relação do professor com o objeto artístico literário e os medias é um dos problemas principais no ensino de literatura na era da reprodutibilidade. Notamos que alguns professores perdem de vista a literatura quando se deparam com os Parâmetros Curriculares para a segunda fase do ensino fundamental e acabam por "usá-la" inadequadamente.

Grandes autores e filósofos refletiram sobre a má relação do leitor com a obra, Mario Vargas Llosa (2009), por exemplo, afirma que nunca se leu tanto texto ruim. Isso é um reflexo da sociedade de consumo e da falta de tempo para apreciação de livros mais complexos, como o apontado por Benjamin (2012). São argumentos pertinentes que, em vez de levarem o professor ao desanimo, podem estimulá-lo a tentar mudar a realidade utilizando os artefatos que muitos dizem concorrer com a literatura para dar o devido espaço e respeito a ela.

O professor interessado na formação estética literária do aluno deve compreender o seu tempo sem perder de vista os tesouros literários que compõem ou não o cânone. Nessa perspectiva, é necessário elaborar estratégias de mediação que possibilitem ao aluno acessar a obra e sua fortuna crítica. Não podemos nos prender ao livro didático ou a questões periféricas à obra, devemos apresentar o universo poético e ficcional da literatura aos alunos de forma integral e através dos meios que disponibilizamos. Essas são apenas possibilidades 
de emancipação intelectual, crítica e estética dos alunos; no entanto, elas podem contribuir para que a literatura atravesse os muros da escola e ganhe lugar cativo nas estantes dos futuros adultos que tivemos, temos e teremos a oportunidade de ensinar.

\title{
LITERATURE, THEATER AND CINEMA: POSSIBLES MEDIATIONS TO WILLIAM SHAKESPEARE IN JUNIOR HIGH SCHOOL
}

\begin{abstract}
We bring a critical-reflective overview of the literature classes in junior high school. This work questions the teacher's relationship with the contemporary media to examine matters related to the reading of aesthetic enjoyment and the possibilities of mediation between students and literary works. These topics converge on the teaching practices carried out in the class of the 8th year of the Centro de Ensino e Pesquisa Aplicada à Educação (CEPAE-UFG), in which we worked with the plays: Romeo and Juliet (1591/95) and Dream of a Summer Night (1595/96), both by William Shakespeare, and by its developments in art and culture.
\end{abstract}

Keywords: Literature teaching; Junior high school; Art; Mediation

\section{LITERATURA, TEATRO Y CINE: MEDIACIONES POSIBLES PARA WILLIAM SHAKESPEARE EN EL SEGUNDO CICLO DE LA EDUCACIÓN PRIMARIA}

\begin{abstract}
Resumen
Traemos una visión crítico-reflexivo de las clases de literatura en la segunda etapa de la educación primaria. Cuestiona la relación del profesor con los medios de comunicación contemporáneos para examinar los asuntos relacionados con la lectura de goce estético y las posibilidades de mediación entre los estudiantes y las obras literarias. Estos temas convergen en las prácticas docentes llevadas a cabo en la clase del octavo año del Centro de Ensino e Pesquisa Aplicada à Educação (CEPAE-UFG), en la que el trabajamos com las piezas teatrales: Romeo y Julieta (1591/95) y El sueño de una noche de verano (1595/96), ambos de
\end{abstract}


William Shakespeare, y sus desarrollos en el arte y la cultura.

Palabras clave: Enseñanza de la Literatura; Segunda fase de la educación primaria; Arte; Mediación

\section{REFERÊNCIAS}

ANDRADE, Carlos Drummond. Alguma poesia. São Paulo: Companhia das Letras, 2013.

BAKHTIN, Mikhail. Estética da criação verbal. Tradução de Paulo Bezerra. São Paulo: Martins Fontes, 2003.

BENJAMIN, Walter. A obra de arte na era de sua reprodutibilidade técnica. Primeira versão. In: Magia e técnica, arte e política: ensaios sobre literatura e história da cultura. Tradução Sergio Paulo Rouanet. $8^{\circ}$ Ed. São Paulo: Brasilense, 2012.

Experiência e pobreza. In: Magia e técnica, arte e política: ensaios sobre literatura e história da cultura. Tradução Sergio Paulo Rouanet. $8^{\circ}$ Ed. São Paulo: Brasilense, 2012.

BRAGA, Patrícia Colavitti. O ensino de literatura na Era dos extremos. Revista Letra Magna, São Paulo, vol. 3 n. 5, Jul./Dec. 2006. Disponível em: https://sandramaggio.files.wordpress.com/2011/03/literatura-e-ensino.pdf. Acesso em: 12 Maio. 2015.

BRASIL. Ministério da Educação e do Desporto. Parâmetros Curriculares Nacionais $\left(1^{a} a 4^{a}\right.$ séries). Brasília: MEC/SEF, 1997.

. Parâmetros Curriculares Nacionais (5 ${ }^{a}$ a $8^{a}$ séries). Brasília: MEC/SEF, 1998.

CALVINO, Italo. Por que ler os clássicos. Tradução de Nilson Moulin. São Paulo: Cultrix, 1993.

CANDIDO, Antonio. O direito à literatura. In: Vários escritos. $3^{\circ}$ Ed. São Paulo: Duas Cidades, 1995.

. A literatura e a formação do homem. In: Textos de intervenção. São Paulo: Duas

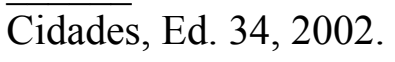

CITELLI, Adilson Odair. Educação e mudanças: novos mundos de conhecer. In:

(Org). Outras linguagens na escola: publicidade, cinema e TV, rádio, jogos, informática. São Paulo: Cortez, 2000.

FREIRE, Paulo. Pedagogia do oprimido. $17^{\circ}$ Ed. Rio de Janeiro: Paz e Terra, 1987.

GIACOMANTONIO, Marcello. O ensino através dos audiovisuais. São Paulo: Edusp, 1981. 
HELIODORA, Bárbara. Entrevista com Bárbara Heliodora. Revista Crop, São Paulo: USP, vol. $07, \quad$ n. $07, \quad$ Jul./Dec. 2001. Disponível em: http://200.144.182.130/revistacrop/images/stories/edicao7/v07a00 apresentao.pdf. Acesso em: 12 Maio. 2015.

LLOSA, Mario Vargas. Em defesa do romance. Revista Piauí, São Paulo, vol. 37, n 01, Out. 2009. Disponível em: http://revistapiaui.estadao.com.br/edicao-37/questoes-literarias/emdefesa-do-romance. Acesso em: 12 Maio. 2015.

PENNAC, Daniel. Como um romance. Tradução de Leny Werneck. Porto Alegre: Rocco, 2008.

RIBEIRO, Claudia Regina; SIQUEIRA, Vera Helena Ferraz. O novo homem na mídia: ressignificações por homens docentes. Estudos Feministas, Florianópolis: UFSC, vol.15 n.1 Jan./Apr. 2007. Disponível em: http://www.scielo.br/pdf/ref/v15n1/a13v15n1. Acesso em: 12 Maio. 2015.

SANTAELLA, Lúcia. Por que as comunicações e as artes estão convergindo? São Paulo: Paulus, 2008.

SHAKESPEARE, William. Romeu e Julieta; Tito Andrônico. Tradução de Carlos Aberto Nunes. Rio de Janeiro: Ediouro, 2004. $\overline{\mathrm{P} \& \mathrm{PM}}, 2001$.

. Sonho de uma noite de verão. Tradução de Beatriz Viégas-Faria. Porto Alegre:

SOUSA, Jorge Pedro. Elementos da teoria e pesquisa da comunicação e dos media. Lisboa: Edições UFP, 2006.

STEINER, George. Alfabetização humanista. In. Linguagem e silêncio: ensaio sobre a crise da palavra. Tradução: Gilda Stuart e Felipe Rajabally. São Paulo: Companhia das letras, 1988.

\section{REFERÊNCIA FÍLMICA}

ROMEU+JULIETA (Romeo+Juliet). Direção: Baz Lhurmann. EUA, 1996. 120 minutos.

Data de recebimento: 01/04/2015

Data de aceite: 14/04/2015 